\title{
Evaluation of rapid alternative methods for drug susceptibility testing in clinical isolates of Mycobacterium tuberculosis
}

\author{
Luciano Mengatto, Yosena Chiani, María Susana Imaz/ ${ }^{+}$
}

Instituto Nacional de Enfermedades Respiratorias “E. Coni”, Blas Parera 8260, Santa Fe (3000) Argentina

\begin{abstract}
A study was carried out to compare the performance of a commercial method (MGIT) and four inexpensive drug susceptibility methods: nitrate reductase assay (NRA), microscopic observation drug susceptibility (MODS) assay, MTT test, and broth microdilution method (BMM). A total of 64 clinical isolates of Mycobacterium tuberculosis were studied. The Lowenstein-Jensen proportion method (PM) was used as gold standard. MGIT, NRA, MODS, and MTT results were available on an average of less than 10 days, whereas BMM results could be reported in about 20 days. Most of the evaluated tests showed excellent performance for isoniazid and rifampicin, with sensitivity and specificity values $>90 \%$. With most of the assays, sensitivity for ethambutol was low (62-87\%) whereas for streptomycin, sensitivity values ranged from 84 to 100\%; NRA-discrepancies were associated with cultures with a low proportion of EMB-resistant organisms while most discrepancies with quantitative tests (MMT and BMM) were seen with isolates whose minimal inhibitory concentrations fell close the cutoff. MGIT is reliable but still expensive. $N R A$ is the most inexpensive and easiest method to perform without changing the organization of the routine PM laboratory performance. While MODS, MTT, and BMM, have the disadvantage from the point of view of biosafety, they offer the possibility of detecting partial resistant strains. This study shows a very good level of agreement of the four low-cost methods compared to the PM for rapid detection of isoniazid, rifampicin and streptomycin resistance (Kappa values > 0.8); more standardization is needed for ethambutol.
\end{abstract}

Key words: drug-susceptibility testing - Mycobacterium tuberculosis - rapid methods

The emergence of tuberculosis in conjunction with the increasing number of multi-drug resistant strains of Mycobacterium tuberculosis has increased the need for rapid and reliable methods of diagnosis and drug susceptibility testing (DST).

The Lowenstein-Jensen (LJ) or agar proportion method (PM) (Canetti et al. 1963, 1969, Kent \& Kubica 1985 ) and the radiometric method in BACTEC TB-460 system (Becton-Dickinson) (Roberts et al. 1983) are the current standard methods recommended to perform susceptibility testing of M. tuberculosis. However they are either time consuming or require the use of radioisotopes, that should be disposed of. Recently, new commercial methods were developed, including mycobacterial growth Indicator Tube (MGIT) (Rusch-Gerdes et al. 1999) and molecular tests such as INNOLIPA Rif TB (Innogetics, Ghent, Belgium) (Rossau et al. 1997). However they are rapid, but expensive, making them impractical for use in developing countries.

A number of new simple and inexpensive methods for drug susceptibility testing have been recently described. The microscopic observation drug susceptibility (MODS) assay is a liquid culture method based on microscopic detection of characteristic M. tuberculosis morphology (Caviedes et al. 2000). The broth microdilution method (BMM) has shown to be a practical and rapid method to determine minimum inhibitory concentrations (MICs)

${ }^{+}$Corresponding author: suimaz@yahoo.com

Received 29 January 2006

Accepted 24 May 2006 of antituberculosis drugs (Leite el al. 2000, Coban et al. 2004). To improve the mycobacterial growing reading, an association of this method with colorimetric compounds, like the oxidation-reductor indicator MTT [3-(4.5dimethylthiazol-2-yl)-2.5-diphenyltetrazolium bromide] has been successfully used (Caviedes et al. 2002). Another new method recently developed is the nitrate reductase assay (NRA) based on the ability of M. tuberculosis to reduce nitrate to nitrite; the reduction can be detected by using specific reagents which produce color change (Angeby et al. 2002).

In the present study 64 clinical isolates of $M$. tuberculosis were tested by a commercial method (MGIT) and four inexpensive methods for DST: the MODS assay, the BMM, the MTT reduction test, and the NRA. The ensuing overall comparison provides a convenient frame of reference for the reliability of these rapid DST methods in the routine of the micobacteriology laboratories.

\section{MATERIALS AND METHODS}

Strains and inoculum preparation - A total of 64 clinical isolates and H37Rv ATCC 27294 (sensitive to all the antituberculosis agents) were evaluated in this study. The M. tuberculosis strains were obtained from 64 different patients whose isolates were referred to the Laboratory of the National Institute of Respiratory Diseases "E. Coni" (Santa Fe, Argentine) for drug susceptibility testing between 2003 and 2005. All clinical isolates were grown in LJ medium and tested in a blind manner for all different methods. The strains were defined as M. tuberculosis according to growth rates, pigmentation, colony properties, and routine biochemical methods (catalase, nitrate reduction, and niacin accumulation tests) (Centro Panamericano de Zoonosis 1988). Colonies from LJ were transferred to a 
tube containing 6-9 sterile glass beads and 3-4 $\mathrm{ml}$ of 7H9S broth [Middlebrook 7H9 broth base (Difco, Sparks, MD, US; $4.7 \mathrm{~g} / \mathrm{l}$ ), with $0.2 \%$ glycerol, supplemented with $10 \%$ oleic-albumin-dextrose-catalase (OADC; Becton Dickinson, Sparks, MD, US)]. Tubes were vigorously agitated and clumps were allowed to settle $30 \mathrm{~min}$. The supernatants were then adjusted with distilled water to equal the density of a $0.5 \mathrm{McF}$ arland standard to be used in the BMM, MGIT, and MODS assays and to equal the density of a 1 McFarland standard to be used in the NRA, PM, and MTT assays. The reference H37Rv was tested each time the experiences were performed with clinical isolates.

Antituberculous drugs - Rifampicin (RIF), isoniazid (INH), ethambutol (EMB), and streptomycin (SM) were obtained in powder form from Sigma Chemical Co (St Louis, MO, US). Stock solutions of INH, EMB, and SM were prepared in deionized water at $10 \mathrm{~g} / \mathrm{l}$ and RIF was prepared in dimethylsulfoxide at $20 \mathrm{~g} / \mathrm{l}$. Stock solutions were kept at $-20^{\circ} \mathrm{C}$ for no more than one month.

$P M$ - The PM was performed on LJ medium according to Canetti et al. (1963) with the recommended critical concentrations of $0.2 \mu \mathrm{g} / \mathrm{ml}$ for INH, $40 \mu \mathrm{g} / \mathrm{ml}$ for RIF, $2 \mu \mathrm{g} /$ $\mathrm{ml}$ for $\mathrm{EMB}$, and $4 \mu \mathrm{g} / \mathrm{ml}$ for SM. To define drug-susceptible from drug-resistant organisms, the PM was considered the gold standard.

MODS assay - This assay was performed in sterile 24well plates (Falcon, Becton Dickinson, Franklin Lakes, NJ, US). To prepare the inoculum, the bacterial suspension, adjusted to a turbidity equivalent to that of a $0.5 \mathrm{McF}$ arland standard, was diluted to $10^{-3}$ in $7 \mathrm{H} 9-\mathrm{S}$ broth. Antibiotic working solutions were prepared at the following concentrations: INH, 1 and $4 \mu \mathrm{g} / \mathrm{ml}$; RIF, 5 and $10 \mu \mathrm{g} / \mathrm{ml}$; EMB, 25 and $37.5 \mu \mathrm{g} / \mathrm{ml} ; \mathrm{SM}, 20$ and $60 \mu \mathrm{g} / \mathrm{ml}$. Five hundred and forty microliters aliquots of diluted bacterial samples were distributed in wells of a 24-well plate. For each isolate, a $60 \mu \mathrm{l}$ aliquot of each one of the drug working solutions was added. Sixty microliters of 7H9-S broth was added in a drug-free control well containing the diluted bacterial suspension. Each plate contained an additional well of drug-free medium; no bacteria were inoculated into this well, which served as a control for cross contamination. Plates were covered and sealed with plastic bags and incubated at $37^{\circ} \mathrm{C}$ in normal atmosphere. Starting on day 3, every 1 or 2 days, wells were examined for the presence of mycobacteria under an inverted light microscope $(\times 40$ magnification). For the purposes of this study, growth was defined as the emergence of visually detectable serpentine clusters of bacteria. If there was growth in the control well then drug-containing wells were visualized on the same day; growth in the presence of drug was regarded as resistant whereas no growth in the presence of drug was considered as susceptible. The final drug concentrations were: INH, 0.1 and $0.4 \mu \mathrm{g} / \mathrm{ml}$; RIF, 0.5 and $1 \mu \mathrm{g} / \mathrm{ml}$; EMB, 2.5 and $3.75 \mu \mathrm{g} / \mathrm{ml} ; \mathrm{SM}, 2$ and $6 \mu \mathrm{g} / \mathrm{ml}$ (Caviedes et al. 2000, Moore et al. 2004).

MGIT - MGIT susceptibility testing was performed according to the manufacturer's recommendations. For each isolate tested, three tubes were prepared: two contained the antituberculosis drugs, and one was a drug- free growth control. To all tubes, $0.5 \mathrm{ml}$ of MGIT OADC growth supplement (Becton Dickinson, Sparks, MD, US) was added, and $0.1 \mathrm{ml}$ of the antibiotic solution was also added to each one of the drug-containing tubes, giving a final concentration of $0.1 \mu \mathrm{g}$ INH per ml and $1 \mu \mathrm{g}$ RIF per $\mathrm{ml}$. All three tubes were then inoculated with $0.5 \mathrm{ml}$ of a $1: 5$ dilution (in distilled water) of a standard inoculum, tightly capped, and incubated at $37^{\circ} \mathrm{C}$. A positive MGIT control tube was prepared by adding $5 \mathrm{ml}$ of a $0.4 \%$ sodium sulphite solution to an empty MGIT tube. An uninoculated MGIT tube, showing minimal or no fluorescence, served as negative control. Starting on day 3, tubes were daily examined for fluorescence by placing them on a $365 \mathrm{\eta m}$ UV transiluminator. An isolate was considered as susceptible whenever the tube containing the drug did not fluoresce within two days after the growth control tube fluoresced, and as resistant whenever the tube with the drug was positive within 2 days of the positivity of the growth control.

NRA - The NRA was performed as described by Angeby et al. (2002). Briefly, the antibiotic was included in LJ medium at a concentration of: $0.2 \mu \mathrm{g} / \mathrm{ml}$ for INH, 40 $\mu \mathrm{g} / \mathrm{ml}$ for RIF, $2 \mu \mathrm{g} / \mathrm{ml}$ for EMB, and $4 \mu \mathrm{g} / \mathrm{ml}$ for SM; 1000 $\mathrm{mg} / \mathrm{l}$ of potassium nitrate $\left(\mathrm{KNO}_{3}\right)$ was also added. Part of the inoculum, adjusted to equal the density of a 1 McFarland standard, was diluted 1:10 in distilled water. For each isolate, $0.2 \mathrm{ml}$ of the undiluted inoculum was added into the tubes containing $\mathrm{LJ}$ medium with $\mathrm{KNO}_{3}$ and the antituberculosis drugs; and $0.2 \mathrm{ml}$ of the $1: 10$ dilution was inoculated into drug-free media containing $\mathrm{KNO}_{3}$ (tubes in triplicate), serving the last three ones as control growth. Tubes were incubated at $37^{\circ} \mathrm{C}$ for 14 days and $0.5 \mathrm{ml}$ of a mixture of three reagents ( 1 part $50 \%$ concentrated hydrochloric acid, 2 parts $0.2 \%$ sulfanilamide and 2 parts $0.1 \% \mathrm{~N}$-1-naphthylenthylenediamine dihydrochloride) was added to one drug-free control tube after 7 days of incubation. If its colour changed to pink then tubes with drugs were tested on the same day. An isolate was considered resistant if there was a colour change in the drug-tube greater than in the 1:10 diluted growth control. If the drug-free control tube did not show any colour change and remained the same, the remaining tubes were further incubated, and the procedure repeated on days 10 and 14 respectively.

MTT assay - The MTT assay was done as described by Caviedes et al. (2002). Briefly, to prepare the inoculum, the bacterial suspension adjusted to equal the density of a $1 \mathrm{McF}$ arland standard was diluted 1:25 with $7 \mathrm{H} 9-\mathrm{S}$ broth and $100 \mu \mathrm{l}$ was used as an inoculum. Two hundred microliters volume of sterile water was added to all outer wells of sterile 96-well plates (Cellstar, Griener Bio-one, Frickenhausen, Germany). One hundred microliters volume of 7H9-S broth was added in each well and serial twofold dilutions of each drug were prepared directly on the plate by adding $100 \mu \mathrm{l}$ of the drug working solutions (prepared at four-fold the highest concentration tested on the plates). The final drug concentration ranges were as follows: 0.125 to $32 \mu \mathrm{g} / \mathrm{ml}$ for INH, 0.062 to $16 \mu \mathrm{g} / \mathrm{ml}$ for RIF, 0.5 to $128 \mu \mathrm{g} / \mathrm{ml}$ for EMB and 0.125 to $32 \mu \mathrm{g} / \mathrm{ml}$ for SM. One hundred microliters of the inoculum was added to 
the wells. Six growth controls containing no antibiotic were included for each isolate. The plates were sealed, placed in plastic bags and incubated at $37^{\circ} \mathrm{C}$ at normal atmosphere. On day-5, $50 \mu \mathrm{l}$ of the tetrazolium-Tween 80 mixture $\{1.5 \mathrm{ml}$ of tetrazolium[3-(4,5-dimethylthiazol-2-yl)2,5diphenyl-tetrazolium bromide] [ICN Biomedicals, Aurora, Oh, US] at a dilution of $1 \mathrm{mg} / \mathrm{ml}$ in absolute ethanol and $1.5 \mathrm{ml}$ of $10 \%$ Tween 80$\}$ was added to one growth control and the plate was then incubated at $37^{\circ} \mathrm{C}$ for $24 \mathrm{~h}$. If this well turned purple, the tetrazolium-Tween 80 mixture was added to all wells and the colour was recorded at $24 \mathrm{~h}$. Otherwise, if the growth control well remained yellow the plate was then incubated at $37^{\circ} \mathrm{C}$ for $24 \mathrm{~h}$, after which tetrazolium-Tween 80 mixture was added to another control before the plate was incubated for another $24 \mathrm{~h}$. If this well remained yellow, incubation was continued and tetrazolium-Tween 80 solution was added to each of the remaining four controls on days $9,11,13$, and 15 . The minimal inhibitory concentration (MIC) was defined as the lowest concentration of each drug that prevented the colour change and the strains were considered susceptible to each drug, if their MICs were below or equal to the critical concentration reported by Montoro et al. (2005); INH, $0.25 \mu \mathrm{g} / \mathrm{ml}$; RIF, $0.25 \mu \mathrm{g} / \mathrm{ml}$; EMB, $4 \mu \mathrm{g} / \mathrm{ml}$; SM, 1 $\mu \mathrm{g} / \mathrm{ml}$.

BMM assay - This assay was performed in sterile 96well plates (Cellstar) as described by Leite el al. (2000) with minor modifications. Briefly, to prepare the inoculum, the bacterial suspension adjusted to equal the density of a 0.5 McFarland standard was diluted 1:25 with $7 \mathrm{H} 9-\mathrm{S}$ broth and $100 \mu \mathrm{l}$ was used as an inoculum. One hundred microliters volume of 7H9-S broth was added in each well and serial two-fold dilutions of each drug were prepared directly on the plate by adding $100 \mu \mathrm{l}$ of the drug working solutions (prepared at four-fold the highest concentration tested on the plates). The final drug concentrations obtained were the same as described before for MTT. One hundred microliters of the inoculum was added to the wells. A well without antimycobacterial agent was also inoculated with $10^{-2}$ dilution of the inoculum as growth control. The plates were sealed, placed in plastic bags and incubated at $37^{\circ} \mathrm{C}$ for 28 days in normal atmosphere. MIC was defined as the lowest drug concentration that exhibited no growth by visual reading, and the strains were considered susceptible to each drug, if their MICs were below or equal to the critical concentration reported by Wallace et al. (1986); INH, $1 \mu \mathrm{g} / \mathrm{ml}$; RIF, $1 \mu \mathrm{g}$ / $\mathrm{ml}$; EMB, $8 \mu \mathrm{g} / \mathrm{ml}$; SM, $2 \mu \mathrm{g} / \mathrm{ml}$.

Costs - All costs were calculated using recent purchase records. Costs for labor were not included.

Data analysis - The performances of the MGIT, MODS, BMM, MTT, and NRA methods in comparison with the PM were evaluated in terms of sensitivity (ability to detect true resistance) and specificity (ability to detect true susceptibility). The agreement between the above mentioned assays and the PM was estimated by the Kappa statistic. The kappa value, a measure of a test reliability, was interpreted as follows: $<0.2$, poor; 0.21 to 0.4 , fair; 0.41 to 0.6 , moderate; 0.61 to 0.8 , good; $>0.81$, excellent (Altman 1999).

\section{RESULTS}

Patterns of susceptibility to INH, RIF, EMB, and SM for $64 \mathrm{M}$. tuberculosis isolates were determined by PM. Out of 64 cultures, 26 (40\%) were resistant to INH, 25 $(39 \%)$ to RIF, $19(30 \%)$ to SM, and $8(13 \%)$ to EMB. Twenty nine cultures were fully drug-susceptible, 7 were monoresistant, 16 were resistant to two drugs and 9 to three drugs.

\section{Susceptibility testing results}

Isoniazid - The PM results with INH were compared with those obtained by the MGIT, NRA, MODS ${ }_{0.4 \mu \mathrm{g} / \mathrm{ml}}$, MODS $_{0.1 \mu \mathrm{g} / \mathrm{ml}}$, MTT, and BMM methods (Table I).

As regards susceptible cultures, only MGIT and MODS $_{0.1 \mu \mathrm{g} / \mathrm{ml}}$ assays, which use a lower INH critical concentration $(0.1 \mu \mathrm{g} / \mathrm{ml})$ than that employs by the reference PM $(0.2 \mu \mathrm{g} / \mathrm{ml})$, misidentified as resistant one of the 38 susceptible cultures (the same isolate in both methods).

Out of 26 INH resistant cultures, three (12\%) were susceptible with MODS $_{0.4 \mu \mathrm{g} / \mathrm{ml}}$ assay; of these three isolates, the MICs by MTT for two isolates were $0.5 \mu \mathrm{g} / \mathrm{ml}$ (one dilution (twofold) higher than the MTT-cutoff value) and the MIC for one isolate was $0.25 \mu \mathrm{g} / \mathrm{ml}$ (at the MTT-cutoff value). Thus, when $0.1 \mu \mathrm{g} / \mathrm{ml}$ was used as critical concentration in MODS method, the agreement was $100 \%$. The NRA, MTT, and BMM assays failed to detect 2, 1, and 3 resistant strains, respectively, whereas MGIT gave $100 \%$ agreement; these discordant results were found in only 3 isolates (the same as in the $\mathrm{MODS}_{0.4 \mathrm{\mu g} / \mathrm{ml}}$ ); although the BMM showed the poorest sensitivity, the MICs of the three discordant strains were only at or one (twofold) dilution lower than the cutoff value.

Sensitivity values for MGIT, NR, $\operatorname{MODS}_{0.4 \mu \mathrm{g} / \mathrm{ml}}$, $\mathrm{MODS}_{0.1 \mu \mathrm{g} / \mathrm{ml}}, \mathrm{MTT}$, and BM methods were 100, 92, 88, 100,96 , and $88 \%$, respectively, and specificity values were $97,100,100,97,100$, and $100 \%$, respectively.

Rifampicin - Complete agreement was found between the results found with the MGIT, NRA, MODS ${ }_{1 \mu \mathrm{g} / \mathrm{ml}}$, MODS $_{0.5 \mu \mathrm{g} / \mathrm{ml}}$, MTT, and BMM methods compared with those obtained with the PM (Table II).

Ethambutol - The PM results with EMB were compared with those obtained by the NRA, $\operatorname{MODS}_{3.75 \mu \mathrm{g} / \mathrm{ml}}$, $\mathrm{MODS}_{2.5 \mu \mathrm{g} / \mathrm{ml}}$, MTT, and BMM methods (Table III).

Specificity values were high in all methods $(98,98,98$, 96 , and $100 \%$ by NR, MODS ${ }_{3.75 \mu \mathrm{g} / \mathrm{ml}}, \mathrm{MODS}_{2.5 \mu \mathrm{g} / \mathrm{ml}}$, MTT, and BM methods, respectively). However, low sensitivities were obtained with most of the tests, with values of $75,62,75,87$, and $62 \%$ by the NRA, $\mathrm{MODS}_{3.75 \mu \mathrm{g} / \mathrm{ml}}$, $\mathrm{MODS}_{2.5 \mu \mathrm{g} / \mathrm{ml}}$, MTT, and BMM methods, respectively. The two discordant results designated resistant by the PM and susceptible by the NRA were found in cultures with only a very small proportion of their bacterial population (between 1 to $10 \%$ ) that was detected to be EMB-resistant by the PM (cultures designated as borderline; Siddiqi et al. 1985). The MICs of most of the discordant results (2 of the 3 isolates) designated resistant by the PM and susceptible by BMM were found to be at the cutoff value. The same cultures were associated with the discordant results obtained with MTT and MODS assays. 
Streptomycin - The PM results with SM were compared with those obtained by the NRA, $\operatorname{MODS}_{6 \mu \mathrm{g} / \mathrm{ml}}$, MODS $_{2 \mu \mathrm{g} / \mathrm{ml}}$, MTT, and BMM methods (Table IV).

As regards susceptible isolates, only MTT and BMM methods misidentified as resistant three and two cultures, respectively. None of the isolates classified as susceptible by the PM were highly resistant by MTT and BMM methods; their corresponding MICs by MTT and BMM methods were only one (twofold) dilution higher than the cutoff value of each method.

TABLE I

Isoniazid susceptibility test results by different techniques

\begin{tabular}{|c|c|c|c|c|c|c|c|c|c|c|c|c|}
\hline \multirow{4}{*}{$\begin{array}{l}\text { Proportion } \\
\text { method }\end{array}$} & \multirow{4}{*}{$\begin{array}{l}\text { No. of } \\
\text { isolates }\end{array}$} & \multicolumn{11}{|c|}{$\begin{array}{c}\text { Determination } \\
\text { (Drug critical concentration } \mu \mathrm{g} / \mathrm{ml} \text { ) }\end{array}$} \\
\hline & & \multirow{2}{*}{\multicolumn{2}{|c|}{$\begin{array}{c}\text { MGIT } \\
(0.1) \\
\text { No. }(\%)\end{array}$}} & \multirow{2}{*}{\multicolumn{2}{|c|}{$\begin{array}{c}\text { NRA } \\
(0.2) \\
\text { No. }(\%)\end{array}$}} & \multirow{2}{*}{\multicolumn{2}{|c|}{$\begin{array}{c}\text { MODS } \\
(0.4) \\
\text { No. }(\%)\end{array}$}} & \multirow{2}{*}{\multicolumn{2}{|c|}{$\begin{array}{c}\text { MODS } \\
(0.1) \\
\text { No. }(\%)\end{array}$}} & \multirow{2}{*}{\multicolumn{2}{|c|}{$\begin{array}{c}\text { MTT }^{a} \\
(0.25)^{a} \\
\text { No. }(\%)\end{array}$}} & \multirow{2}{*}{$\begin{array}{c}\text { BMM } \\
(1)^{a} \\
\text { No. }(\%)\end{array}$} \\
\hline & & & & & & & & & & & & \\
\hline & & $\mathrm{R}$ & $\mathrm{S}$ & $\mathrm{R}$ & S & $\mathrm{R}$ & S & $\mathrm{R}$ & S & $\mathrm{R}$ & S & $\mathrm{R} \quad \mathrm{S}$ \\
\hline Resistant & 26 & $26(100)$ & $0(0)$ & $24(92)$ & $2(8)$ & $23(88)$ & 3 (12) & $26(100)$ & $0(0)$ & $25(96)$ & $1(4)$ & $23(88) \quad 3(12)$ \\
\hline Susceptible & 38 & $1(3)$ & $37(97)$ & $0(0)$ & $38(100)$ & $0(0)$ & $38(100)$ & $1(3)$ & $37(97)$ & $0(0)$ & $38(100)$ & $0(0) 38(100)$ \\
\hline Kappa value & & & $.97^{b}$ & & $93^{b}$ & 0.90 & & $0.97^{b}$ & & $0.97^{b}$ & & $0.90^{b}$ \\
\hline
\end{tabular}

MGIT: mycobacterial growth indicator tube; NRA: nitrate reductase assay; MODS: microscopic observation drug susceptibility; MTT: MTT reduction test; BMM: broth microdilution method; $a$ : in quantitative tests, the cutoff value could be considered the critical concentration used for other drug susceptibility tests to separate susceptible from resistant isolates.

The Kappa value is a measure of test reliability with values interpreted as follows: $\leq 0.2$, poor; 0.21 to 0.4 , fair; 0.41 to 0.6 , moderate; 0.61 to 0.8 , good; $\geq 0.81$, excellent; $b: \mathrm{p}<0.001$.

TABLE II

Rifampicin susceptibility test results by different techniques

\begin{tabular}{|c|c|c|c|c|c|c|c|c|c|c|c|c|}
\hline \multirow{4}{*}{$\begin{array}{l}\text { Proportion } \\
\text { method }\end{array}$} & \multirow{4}{*}{$\begin{array}{l}\text { No. of } \\
\text { isolates }\end{array}$} & \multicolumn{11}{|c|}{$\begin{array}{c}\text { Determination } \\
\text { (Drug critical concentration } \mu \mathrm{g} / \mathrm{ml} \text { ) }\end{array}$} \\
\hline & & \multirow{2}{*}{\multicolumn{2}{|c|}{$\begin{array}{c}\text { MGIT } \\
(1) \\
\text { No. }(\%)\end{array}$}} & \multirow{2}{*}{\multicolumn{2}{|c|}{$\begin{array}{c}\text { NRA } \\
(40) \\
\text { No. }(\%)\end{array}$}} & \multirow{2}{*}{\multicolumn{2}{|c|}{$\begin{array}{c}\text { MODS } \\
(1) \\
\text { No. }(\%)\end{array}$}} & \multirow{2}{*}{\multicolumn{2}{|c|}{$\begin{array}{c}\text { MODS } \\
(0.5) \\
\text { No. }(\%)\end{array}$}} & \multirow{2}{*}{\multicolumn{2}{|c|}{$\begin{array}{c}\text { MTT }^{a} \\
(0.25)^{a} \\
\text { No. }(\%)\end{array}$}} & \multirow{2}{*}{$\begin{array}{c}\text { BMM } \\
(1)^{a} \\
\text { No. }(\%)\end{array}$} \\
\hline & & & & & & & & & & & & \\
\hline & & $\mathrm{R}$ & S & $\mathrm{R}$ & S & $\mathrm{R}$ & S & $\mathrm{R}$ & $\mathrm{S}$ & $\mathrm{R}$ & S & $\mathrm{R} \quad \mathrm{S}$ \\
\hline Resistant & 25 & $25(100)$ & $0(0)$ & $25(100)$ & $0(0)$ & 25 (100) & $0(0)$ & $25(100)$ & $0(0) \quad 2$ & $25(100)$ & $0(0)$ & $25(100) \quad 0(0)$ \\
\hline Susceptible & 39 & $0(0)$ & $39(100)$ & $0(0)$ & $39(100)$ & $0(0)$ & $39(100)$ & $0(0)$ & 39 (100) & $0(0)$ & $39(100)$ & $0(0) 39(100)$ \\
\hline Kappa value & & 1.00 & & 1.00 & & 1.00 & $0^{b}$ & 1.00 & & 1.00 & & $1.00^{b}$ \\
\hline
\end{tabular}

MGIT: mycobacterial growth indicator tube; NRA: nitrate reductase assay; MODS: microscopic observation drug susceptibility; MTT: MTT reduction test; BMM: broth microdilution method; $a$ : in quantitative tests, the cutoff value could be considered the critical concentration used for other drug susceptibility tests to separate susceptible from resistant isolates.

The Kappa value is a measure of test reliability with values interpreted as follows: $\leq 0.2$, poor; 0.21 to 0.4 , fair; 0.41 to 0.6 , moderate; 0.61 to 0.8 , good; $\geq 0.81$, excellent; $b: \mathrm{p}<0.001$.

TABLE III

Ethambutol susceptibility test results by different techniques

\begin{tabular}{|c|c|c|c|c|c|c|c|c|c|c|c|}
\hline \multirow{4}{*}{$\begin{array}{l}\text { Proportion } \\
\text { method }\end{array}$} & \multirow{4}{*}{$\begin{array}{l}\text { No. of } \\
\text { isolates }\end{array}$} & \multicolumn{10}{|c|}{$\begin{array}{c}\text { Determination } \\
\text { (Drug critical concentration } \mu \mathrm{g} / \mathrm{ml} \text { ) }\end{array}$} \\
\hline & & \multirow{2}{*}{\multicolumn{2}{|c|}{$\begin{array}{c}\text { NRA } \\
(2) \\
\text { No. }(\%)\end{array}$}} & \multirow{2}{*}{\multicolumn{2}{|c|}{$\begin{array}{c}\text { MODS } \\
(3.75) \\
\text { No. }(\%)\end{array}$}} & \multirow{2}{*}{\multicolumn{2}{|c|}{$\begin{array}{c}\text { MODS } \\
(2.5) \\
\text { No. }(\%)\end{array}$}} & \multirow{2}{*}{\multicolumn{2}{|c|}{$\begin{array}{c}\text { MTT }^{a} \\
\text { (4) }{ }^{a} \\
\text { No. }(\%)\end{array}$}} & \multirow{2}{*}{\multicolumn{2}{|c|}{$\begin{array}{c}\text { BMM } \\
(8)^{a} \\
\text { No. }(\%)\end{array}$}} \\
\hline & & & & & & & & & & & \\
\hline & & $\mathrm{R}$ & $\mathrm{S}$ & $\mathrm{R}$ & S & $\mathrm{R}$ & $\mathrm{S}$ & $\mathrm{R}$ & S & $\mathrm{R}$ & $\mathrm{S}$ \\
\hline Resistant & 8 & $6(75)$ & $2(25)$ & $5(62)$ & $3(38)$ & $6(75)$ & $2(25)$ & $7(87)$ & $1(13)$ & $5(62)$ & $3(38)$ \\
\hline Susceptible & 56 & $1(2)$ & $55(98)$ & $1(2)$ & $55(98)$ & $1(2)$ & $55(98)$ & $2(4)$ & $54(96)$ & $0(0)$ & $56(100)$ \\
\hline \multicolumn{2}{|l|}{ Kappa value } & \multicolumn{2}{|c|}{$0.77^{b}$} & \multicolumn{2}{|c|}{$0.68^{b}$} & \multicolumn{2}{|c|}{$0.77^{b}$} & \multicolumn{2}{|c|}{$0.80^{b}$} & \multicolumn{2}{|c|}{$0.74^{b}$} \\
\hline
\end{tabular}

MGIT: mycobacterial growth indicator tube; NRA: nitrate reductase assay; MODS: microscopic observation drug susceptibility; MTT: MTT reduction test; BMM: broth microdilution method; $a$ : in quantitative tests, the cutoff value could be considered the critical concentration used for other drug susceptibility tests to separate susceptible from resistant isolates.

The Kappa value is a measure of test reliability with values interpreted as follows: $\leq 0.2$, poor; 0.21 to 0.4 , fair; 0.41 to 0.6 , moderate; 0.61 to 0.8 , good; $\geq 0.81$, excellent; $b: \mathrm{p}<0.001$. 
Out of the 19 SM-resistant cultures, six (32\%) were misidentified as susceptible by MODS $_{6 \mu \mathrm{g} / \mathrm{ml}}$. Of these six isolates with discordant results, the MICs by MTT for one isolate was $0.5 \mu \mathrm{g} / \mathrm{ml}$ (one dilution lower than the MTT-cutoff value), for two isolates were $2 \mu \mathrm{g} / \mathrm{ml}$ (one dilution off the MTT-cutoff value), for two isolates were 4 $\mathrm{mg} / \mathrm{ml}$ and for the remaining isolate was $8 \mu \mathrm{g} / \mathrm{ml}$. Furthermore, when $2 \mu \mathrm{g} / \mathrm{ml}$ was used in MODS method, the percentage of discordant results decreased to $10 \%$ (2 from 19). For NRA, 3 of the 19 resistant isolates were found susceptible, giving a low level of sensitivity (84\%).

Overall, sensitivity values for the NRA, MODS $_{6 \mathrm{ug} / \mathrm{ml}}$, MODS $_{2 \mu \mathrm{g} / \mathrm{ml}}$, MTT, and BMM methods were 84, 68, 89,95, and $100 \%$, respectively, whereas the specificity values were $100,100,100,93$, and $96 \%$, respectively.

Costs - Table V shows the estimated costs per strain for susceptibility testing. Costs were calculated for two first-line anti-TB drugs (INH and RIF), and for four firstline drugs (INH, RIF, EMB, SM). Items included in cost analysis are noted below the Table.

Turnaround time (TAT) - The average time required to obtain a susceptibility result by the MGIT, NRA, MODS, and MTT methods was 6.4 days (range, 3 to 13), 9 days (range, 7 to 14), 7 days (range, 4 to 14 ) and 7.7 days (range, 7 to 17), respectively. As regards BMM, MICs could be read when organisms had reached good macroscopic growth in control wells, generally after 14-17 days, but the reading was repeated every two days up to day 28 of incubation. More than half of the strains had no change in the MIC value from day 14 to 20 of incubation; almost $75 \%$ of changes involving only one dilution. None of the strains had change in MICs after day 20 of incubation. Furthermore, considering some authors' concerns on the fact that early readings might result in false susceptibility if a heterogeneous population of resistance was present, we chose to use the 20-day reading time (Wallace et al. 1986).

\section{DISCUSSION}

Recently, new methods for rapid determination of $M$. tuberculosis DST have been described, viz MGIT, NRA, MODS, MTT, and BMM assays. In practice, these methods vary greatly, especially in the type of medium used and in the drug concentration in the medium. Each method has been successfully tested in previous studies (RuschGerdes et al. 1999, Leite el al. 2000, Caviedes et al. 2000, 2002, Angeby et al. 2002, Park et al. 2002), showing that

TABLE IV

Streptomycin susceptibility test results by different techniques

\begin{tabular}{|c|c|c|c|c|c|c|c|c|c|c|c|}
\hline \multirow{3}{*}{$\begin{array}{l}\text { Proportion } \\
\text { method }\end{array}$} & \multirow{3}{*}{$\begin{array}{r}\text { No. of } \\
\text { isolates }\end{array}$} & \multicolumn{10}{|c|}{$\begin{array}{c}\text { Determination } \\
\text { (Drug critical concentration } \mu \mathrm{g} / \mathrm{ml} \text { ) }\end{array}$} \\
\hline & & \multicolumn{2}{|c|}{$\begin{array}{c}\text { NRA } \\
(4) \\
\text { No. }(\%)\end{array}$} & \multicolumn{2}{|c|}{$\begin{array}{c}\text { MODS } \\
(6) \\
\text { No. }(\%)\end{array}$} & \multicolumn{2}{|c|}{$\begin{array}{c}\text { MODS } \\
(2) \\
\text { No. }(\%)\end{array}$} & \multicolumn{2}{|c|}{$\begin{array}{c}\text { MTT } \\
(1)^{a} \\
\text { No. }(\%)\end{array}$} & \multicolumn{2}{|c|}{$\begin{array}{c}\text { BMM } \\
(2)^{a} \\
\text { No. }(\%)\end{array}$} \\
\hline & & $\mathrm{R}$ & S & $\mathrm{R}$ & $\mathrm{S}$ & $\mathrm{R}$ & $\mathrm{S}$ & $\mathrm{R}$ & S & $\mathrm{R}$ & $\mathrm{S}$ \\
\hline Resistant & 19 & $16(84)$ & 3 (16) & $13(68)$ & $6(32)$ & 17 (89) & $2(11)$ & $18(95)$ & $1(5)$ & $19(100)$ & $0(0)$ \\
\hline Susceptible & 45 & $0(0)$ & 45 (100) & $0(0)$ & $45(100)$ & $0(0)$ & $45(100)$ & $3(7)$ & $42(93)$ & $2(4)$ & $43(96)$ \\
\hline \multicolumn{2}{|l|}{ Kappa value } & \multicolumn{2}{|c|}{$0.88^{b}$} & \multicolumn{2}{|c|}{$0.75^{b}$} & \multicolumn{2}{|c|}{$0.92^{b}$} & \multicolumn{2}{|c|}{$0.85^{b}$} & \multicolumn{2}{|c|}{$0.93^{b}$} \\
\hline
\end{tabular}

MGIT: mycobacterial growth indicator tube; NRA: nitrate reductase assay; MODS: microscopic observation drug susceptibility; MTT: MTT reduction test; BMM: broth microdilution method; $a$ : in quantitative tests, the cutoff value could be considered the critical concentration used for other drug susceptibility tests to separate susceptible from resistant isolates.

The Kappa value is a measure of test reliability with values interpreted as follows: $\leq 0.2$, poor; 0.21 to 0.4 , fair; 0.41 to 0.6 , moderate; 0.61 to 0.8 , good; $\geq 0.81$, excellent; $b: \mathrm{p}<0.001$.

TABLE V

Cost per strain for susceptibility testing

\begin{tabular}{|c|c|c|}
\hline \multirow[b]{2}{*}{ Method } & \multicolumn{2}{|c|}{ Susceptibility cost (U\$) ${ }^{a}$} \\
\hline & Two drugs & Four drugs \\
\hline Mycobacterial growth indicator tube (MGIT) ${ }^{b}$ & 19.52 & NA \\
\hline Nitrate reductase assay ${ }^{c}$ & 0.17 & 0.24 \\
\hline Microscopic observation drug susceptibility assay ${ }^{d}$ & 1.57 & 2.17 \\
\hline [3-(4.5-dimethylthiazol-2-yl)-2.5-diphenyltetrazolium bromide] (MTT) assay ${ }^{e}$ & 2.23 & 3.96 \\
\hline Broth microdilution method ${ }^{f}$ & 2.07 & 3.63 \\
\hline
\end{tabular}

$a$ : two drugs, INH and RIF; four drugs, INH, RIF, EMB, and SM; $b$ : includes costs of MGIT (prepared tubes), OADC, and antimicrobial drugs; $c$ : includes costs of LJ medium, glycerol, eggs, potassium nitrate, and antimicrobial drugs; $d$ : calculated for two different concentration of each drug. Includes costs of Middlebrook 7H9 medium, glycerol, OADC, 24-well plate (three and two strains per plate for two and four drugs susceptibility testings, respectively), and antimicrobial drugs; $e$ : includes costs of Middlebrook 7H9 medium, glycerol, OADC, MTT reagent, 96-well plate (one and two strains per plate for four and two drug susceptibility testings, respectively), and antimicrobial drugs; $f$ : includes costs of Middlebrook 7H9 medium, glycerol, OADC, 96-well plate (one and two strains per plate for four and two drug susceptibility testings, respectively), and antimicrobial drugs; NA: not applicable. 
results can be obtained faster than with the PM, but, to the best of our knowledge, they have never been compared together.

Our data demonstrated that the evaluated methods have an excellent test performance for INH and RIF (sensitivity and specificity values higher than $90 \%$ with most of the tests). Results with the other first line anti-tuberculosis drugs, SM and EMB, but especially with EMB, showed some discrepancies. Some of the important factors, which may have contributed to these discrepancies, are: (i) a low proportion of drug resistant organisms in the test population of a culture, (ii) substantial differences in the medium used by the methods, and (iii) different periods of incubation, which may be associated with different degrees of degradation of the antimicrobial agent.

In quantitative tests like MTT and BMM methods, the cutoff value is considered the drug concentration that would separate susceptible from resistant isolates. In these tests, this value could be interpreted as the critical concentration used for other DST methods to distinguish susceptible from resistant strains (Heifets 2000). Nevertheless, care should be taken when interpreting MIC values close the critical concentration, since like in some other studies evaluating quantitative DST methods (Franzblau et al. 1998, Luna Herrera et al. 2003), in our work, most discrepancies among the PM and MTT or BMM were seen with isolates whose MICs fell at or one dilution (twofold) higher or lower than the cutoff value. Based on these observations, some authors (Heifets et al. 1990, Franzblau et al. 1998, Luna-Herrera et al. 2003) have suggested the use of a partially resistant range that is close to the cutoff value, proposing the existence of three categories of susceptibility: susceptible, partially resistant (isolates with borderline MICs) and resistant. The use of these categories would allow the identification of TB due to low-level resistant strains, making possible the use of a drug up to near the maximum concentration that it could reach in the human body. In this respect, some evidences indicate that the use of high-dose isoniazid in TB retreatment regimens, in spite of the acquired isoniazid resistance, could improve therapeutic results, if all or part of the organisms were resistant to only a low concentration of that drug (Moulding 1981).

Similarly, the use of double drug critical concentration with MODS test allowed the identification of $11 \%$ (3 of 26) INH-resistant strains and 21\% (4 of 19) SM-resistant strains, that grew in low but not in high concentration of drugs; their corresponding MICs determined by MTT fell into the INH and SM partially resistant ranges proposed by Franzblaw et al. (1998) (between 0.25 and $0.5 \mu \mathrm{g} / \mathrm{ml}$ for INH and between 2 and $8 \mu \mathrm{g} / \mathrm{ml}$ for SM). Therefore, and taking into account these authors' notion of three categories of susceptibility, these strains could be considered low-level resistant strains.

Twenty five percent (2 out of 8) EMB-resistant strains were misidentified as susceptible by NRA. Interestingly, among the eight true EMB-resistant strains, these two cultures were the only ones with a very small - from 1 to $10 \%$ - proportion of the bacterial population showing to be resistant by the PM (cultures designated as borderline; Siddiqi et al. 1985). The NRA was standardized to consider a strain "resistant" when the drug-containing tube inoculated with an undiluted suspension of bacilli exhibited a nitrate reductase (NR) activity greater than that appearing in the 1:10 diluted growth control (where about $10 \%$ of the original inoculum was added). In "borderline" strains, it would be expected that only about less than $10 \%$ of the organisms could grow in the EMB-containing tube, so that it is probable that the NR activity exhibited by the drug-containing tube was lower than that obtained in the 1:10 diluted growth control tube. Furthermore, some authors have shown that these "borderline" cultures, more frequently associated with EMB resistance, have classically caused problems in the interpretation of EMB DST (Siddiqi et al. 1985), adversely affecting the assays overall performance. On the other hand, for SM, a low level of sensitivity was obtained. Similar results were reported by Martin et al. (2005) in their multicenter evaluation of the NRA. A possible interaction between the drugs and the potassium nitrate was speculated as a cause of this discrepancy.

The turnaround time (TAT) is important in order for the patient to receive an appropriate treatment. The results obtained with MGIT, MODS, NRA, and MTT were available on an average of less than 10 days as with the reference method BACTEC-460. The BMM, although consuming more time than the other four evaluated tests, could be still reported faster (about 20 days) than the PM (28-40 days).

Caviedes et al. (2000), in their evaluation of MODS assay for DST, defined a "resistant strain" whenever the growth in the presence of drug is microscopically observed on the same day when the growth in control wells is detected; suggesting that the wells have to be microscopically examined every one or two days. This high frequency of checking obviously yielded the fastest results, and at first, one could anticipate that it would prevent that true susceptible strains could be misidentified as resistant, if the time between the appearance of "any growth in the drug-containing wells" of susceptible cultures and "that in the control wells" were too short. In our study, we tested that this period was about 10 days minimum (during the 28-day incubation period, about $90 \%$ of susceptible strains showed no growth in the drug-containing wells), allowing, if necessary, to perform the microscopic observation at intervals suitable to the laboratory workload, thus adding an operational advantage to this method.

RIF resistance is considered to be a strong predictor of the presence of multidrug-resistant tuberculosis, especially in countries with high prevalence of drug resistance (Rossau et al. 1997). Therefore, the complete agreement in RIF-susceptibility results found for all the methods studied in this work indicates the potential of any of this simple and inexpensive assays for control programs in countries with high levels of tuberculosis endemicity.

In accordance with previous studies, this work showed that MGIT system is a reliable, rapid and convenient method for performing INH and RIF susceptibility tests, but too expensive to implement in low-resources countries. Indeed, cost was the factor that prohibited us its evaluation with EMB and SM. This study showed that 
using low-costs "in house" assays for rapid detection of susceptibility, good or excellent levels of agreement with the PM were obtained. The NRA seems to be the most inexpensive method; the medium used is the classical LJ with the same concentration of antimicrobial drugs that is used for the PM; it is easy to perform without changing the organization of the routine laboratory performing DST. However NRA gives only qualitative results. On the other hand, both microdilution susceptibility tests (MTT and BMM) and MODS assay offer the advantage of identifying partial resistance but have the disadvantage from the point of view of biosafety because manipulation of plates could generate aerosols. Placement of the plate in a transparent plastic bag, appropriately secured, adds an element of biosafety. In this regard, results obtained by MODS and BMM, which are methods based on the direct microscopic or macroscopic growth observation, do not require the addition of any reagent (like in MTT), thus the sealed plates should not be opened and, consequently, the biohazard potential might be reduced in the case that the plate is mishandled.

\section{REFERENCES}

Altman DG 1999. Inter-rater agreement. In Practical Statistics for Medical Research, Chapman \& Hall/CRC, London, p. 403-409.

Angeby KA, Klintz L, Hoffner SE 2002. Rapid and inexpensive drug susceptibility testing of Mycobacterium tuberculosis with a nitrate reductase assay. J Clin Microbiol 40: 553-555.

Canetti G, Froman F, Grosset J, Hauduroy P, Langerova M, Mahler HT, Meissner G, Mitchison DA, Sula L 1963. Mycobacteria: laboratory methods for testing drug sensitivity and resistance. Bull WHO 29: 565-578.

Canetti G, Fox W, Khomenko A, Mahler HT, Menon NK, Mitchison DA, Rist N, Smelev NA 1969. Advances in techniques of testing mycobacterial drug sensitivity, and the use of sensitivity tests in tuberculosis control programmes. Bull WHO 41: 21-43.

Caviedes L, Delgado J, Gilman RH 2002. Tetrazolium microplate assay as a rapid and inexpensive colorimetric method for determination of antibiotic susceptibility of Mycobacterium tuberculosis. J Clin Microbiol 40: 18731874.

Caviedes L, Lee TS, Gilman RH, Sheen P, Spellman E, Lee EH, Berg DE, Montenegro-James S. The Tuberculosis Working Group in Peru 2000. Rapid, efficient detection and drug susceptibility testing of Mycobacterium tuberculosis in sputum by microscopic observation of broth cultures. J Clin Microbiol 38: 1203-1208.

Centro Panamericano de Zoonosis 1988. Tuberculosis bacteriology. Technical note 11, Centro Panamericano de Zoonosis, Buenos Aires, Argentina (In Spanish).

Coban AY, Birinci A, Ekinci B, Durupinar B 2004. Drug susceptibility testing of Mycobacterium tuberculosis by the broth microdilution method with $7 \mathrm{H} 9$ broth. Mem Inst Oswaldo Cruz 99: 111-113.

Franzblau SG, Witzig RS, McLaughlin JC, Torres P, Madico G, Hernandez A, Degnan MT, Cook MB, Quenzer VK, Ferguson RM, Gilman RH 1998. Rapid, low-technology
MIC determination with clinical Mycobacterium tuberculosis isolates by using the microplate Alamar Blue assay. $J$ Clin Microbiol 36: 362-366.

Heifets LB, Lindholm-Levy PJ, Flory M 1990. Bactericidal activity in vitro of various rifamycins against Mycobacterium avium and Mycobacterium tuberculosis. Am Rev Respir Dis 141: 626-630.

Heifets L 2000. Convetional methods for antimycobacterial susceptibility testing of Mycobacterium tuberculosis. In I Bastian, F Portaels (eds), Multidrug Resistant Tuberculosis, Kluwer, Dordrecht, p. 133-144.

Kent PA, Kubica GP 1985. Public Health Mycobacteriology. A guide for the Level III Laboratory. US Department of Health and Human Services, Centers for Disease Control and Prevention, Atlanta.

Leite CQ, Beretta AL, Anno IS, Telles MA 2000. Standardization of broth microdilution method for Mycobacterium tuberculosis. Mem Inst Oswaldo Cruz 95: 127-129.

Luna-Herrera J, Martinez-Cabrera G, Parra-Maldonado R, Enciso-Moreno JA, Torres-Lopez J, Quesada-Pascual F, Delgadillo-Polanco R, Franzblau SG 2003. Use of receiver operating characteristic curves to assess the performance of a microdilution assay for determination of drug susceptibility of clinical isolates of Mycobacterium tuberculosis. Eur J Clin Microbiol Infect Dis 22: 21-27.

Martin A, Montoro E, Lemus D, Simboli N, Morcillo N, Velasco M, Chauca J, Barrera L, Ritacco V, Portaels F, Palomino JC 2005. Multicenter evaluation of the nitrate reductase assay for drug resistance detection of Mycobacterium tuberculosis. J Microbiol Methods 63: 145-150.

Montoro E, Lemus D, Echemendia M, Martin A, Portaels F, Palomino JC 2005. Comparative evaluation of the nitrate reduction assay, the MTT test, and the resazurin microtitre assay for drug susceptibility testing of clinical isolates of Mycobacterium tuberculosis. J Antimicrob Chemother 55: 500-505.

Moore DA, Mendoza D, Gilman RH, Evans CA, Hollm Delgado MG, Guerra J, Caviedes L, Vargas D, Ticona E, Ortiz J, Soto G, Serpa J, Tuberculosis Working Group in Peru 2004. Microscopic observation drug susceptibility assay, a rapid, reliable diagnostic test for multidrug-resistant tuberculosis suitable for use in resource-poor settings. J Clin Microbiol 42: 4432-4437.

Moulding TS 1981. Should isoniazid be used in retreatment of tuberculosis despite acquired isoniazid resistance? Am Rev Respir Dis 123: 262-264.

Park WG, Bishai WR, Chaisson RE, Dorman SE 2002. Performance of the microscopic observation drug susceptibility assay in drug susceptibility testing for Mycobacterium tuberculosis. J Clin Microbiol 40: 4750-7752.

Roberts GD, Goodman NL, Heifets L, Larsh HW, Lindner TH, McClatchy JK, McGinnis MR, Siddiqi SH, Wright P 1983. Evaluation of the BACTEC radiometric method for recovery of mycobacteria and drug susceptibility testing of $M y$ cobacterium tuberculosis from acid-fast smear-positive specimens. J Clin Microbiol 18: 689-396.

Rossau R, Traore H, De Beenhouwer H, Mijs W, Jannes G, De Rijk P, Portaels F 1997. Evaluation of the INNO-LiPA Rif. $\mathrm{TB}$ assay, a reverse hybridization assay for the simulta- 
neous detection of Mycobacterium tuberculosis complex and its resistance to rifampin. Antimicrob Agents Chemother 41: 2093-2098.

Rusch-Gerdes S, Domehl C, Nardi G, Gismondo MR, Welscher HM, Pfyffer GE 1999. Multicenter evaluation of the mycobacteria growth indicator tube for testing susceptibility of Mycobacterium tuberculosis to first-line drugs. J Clin Microbiol 37: 45-48.
Siddiqi SH, Hawkins JE, Laszlo A 1985. Interlaboratory drug susceptibility testing of Mycobacterium tuberculosis by a radiometric procedure and two conventional methods. J Clin Microbiol 22: 919-923.

Wallace RJ, Nash DR, Steele LC, Steingrube V 1986. Susceptibility testing of slowly growing mycobacteria by a microdilution MIC method with 7H9 broth. J Clin Microbiol 24: 976-981. 